\title{
un método para determinar la cantidad de cemento en mortero y hormigón
}

El método se basa en la determinación del porcentaje de calcio en mezcla arena-cemento. El calcio se precipita en el filtrado después del ataque de la muestra por ácido clorhídrico, como oxalato cálcico en presencia de ácido acético glacial sin eliminar la sílice soluble y los sesquióxidos. La proporción de cemento se determina por la cantidad de calcio presente en la muestra. El procedimiento es el siguiente:

La muestra se desmenuza hasta polvo fino. $\mathrm{Si}$ se ha empleado arena gruesa en el mortero u hormigón, se separa pasando la muestra por un tamiz de 40 mallas. Se pesa exactamente un gramo de polvo y se trata en un vaso de vidrio Pyrex con 10 c. c. de solución de $\mathrm{ClH}$ 1: 1 durante cinco minutos en un hornillo eléctrico. La solución se filtra y lava con agua destilada caliente y se diluye hasta 100 c. c. De esta solución 50 c. c. se neutralizan exactamente con hidróxido amónico. Después se añade suficiente ácido acético glacial como para disolver los precipitados de $\mathrm{Al}_{2} \mathrm{O}_{3}, \mathrm{Fe}_{2} \mathrm{O}_{3}, \mathrm{PO}_{4}$, TiO, etc., así formados. Entonces se añade a la solución saturada de oxalato amónico en exceso y se obtiene un abundante precipitado granular blanco de oxalato cálcico. Luego se filtra este precipitado y se lava con agua destilada, disolviśndose más tarde en una solución de $\mathrm{SO}_{4} \mathrm{H}_{2} 1: 4$ caliente. El conjunto se valora con solución de $\mathrm{MnO}_{4} \mathrm{~K}$ standard para determinar el porcentaje de calcio. 


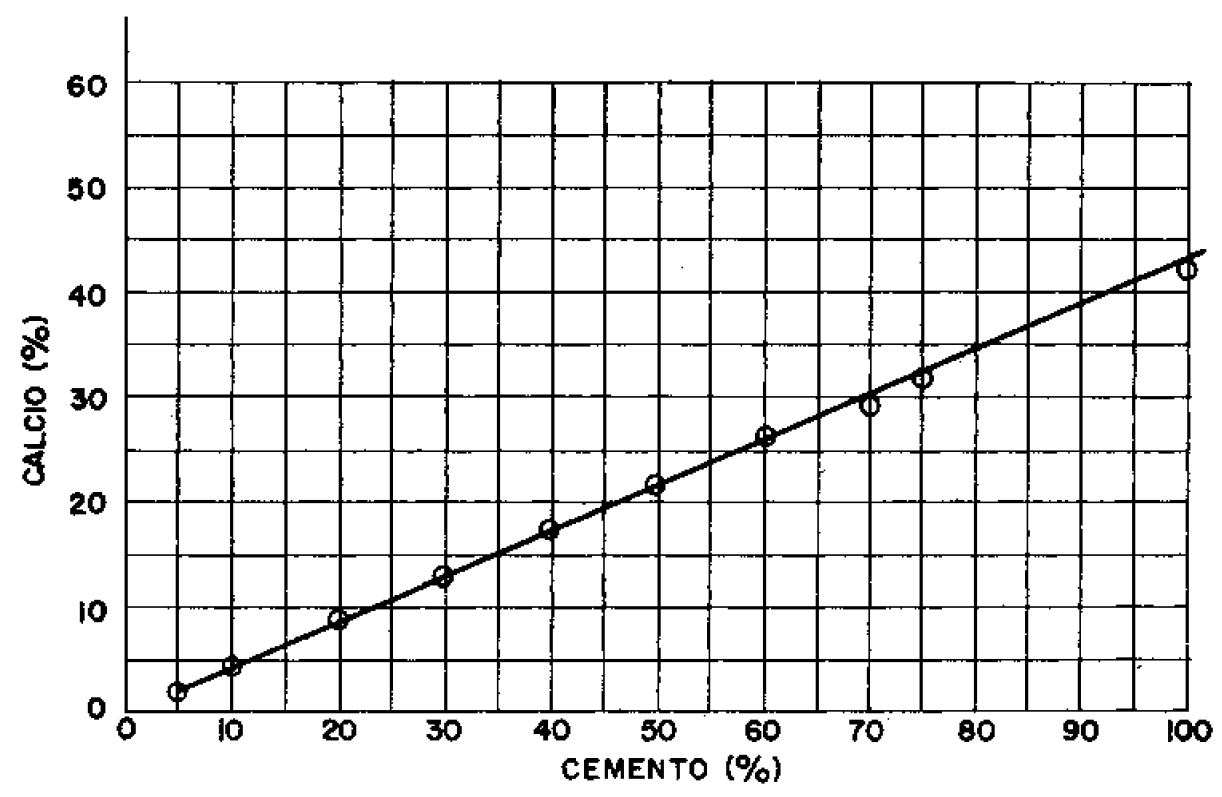

Fig. 1

1 c. c. de una solución $0,1 \mathrm{~N}$ de $\mathrm{MnO}_{4} \mathrm{~K}=0,002 \mathrm{~g} \mathrm{Ca}=$ Valumen en c. c. de solución $0,1 \mathrm{~N}$ de $\mathrm{MnO}_{4} \mathrm{~K}$ requerido $\times 200 \times 0,002=$ volumen en c. c. de solución $0,1 \mathrm{~N}$ de $\mathrm{MnO}_{4} \mathrm{~K}$ $\times 0,4$.

Después de una serie de determinaciones con distintas proporciones de cemento en morteros y hormigones, se ha construído un gráfico con el porcentaje de calcio como ordenada o abscisa y el porcentaje de cemento en el otro eje, resultando una línea recta. Por el gráfico es fácil de determinar el porcentaje de cemento usado en cualquier mezcla cemento-arena 11 hormigón desconocidas, cuando el contenido en calcio de la muestra se ha determinado por el método anterior. En la tabla I y figura 1 se encuentran los resultados típicos de un ensayo.

T A B L A I

Porcentaje de cemento en mezclas cemento-arena

\begin{tabular}{|c|c|c|c|c|}
\hline $\begin{array}{c}\text { Muestra } \\
\text { múm. }\end{array}$ & $\begin{array}{c}\text { Cemento } \\
\text { en } 1 \text { ia } \\
\text { mezctala } \\
(\%)\end{array}$ & $\begin{array}{c}\text { Calcio } \\
\text { en la muestra } \\
\text { reofentemente } \\
\text { preparada } \\
(\%) \\
(\%)\end{array}$ & $\begin{array}{c}\text { Caloio } \\
\text { en prohetas } \\
\text { ouradag } 7 \text { días } \\
(\%)\end{array}$ & $\begin{array}{c}\text { Caleio } \\
\text { en probetas } \\
\text { criradas 28 dias } \\
(\% 6)\end{array}$ \\
\hline 1 & 100 & 42.18 & 39,72 & 39,55 \\
\hline 2 & 75 & 31,80 & - & - \\
\hline 3 & 70 & 29,50 & 29,10 & 29,08 \\
\hline 4 & 60 & 26.45 & 26,20 & 25,20 \\
\hline 5 & 50 & 21,52 & 22,70 & 20,55 \\
\hline 6 & 40 & 17,31 & 16,80 & 17,15 \\
\hline 7 & 30 & 13,01 & 13,04 & 12,96 \\
\hline 8 & 20 & 8,86 & 8,84 & 8,65 \\
\hline 9 & 10 & 4,46 & 4,44 & 4,21 \\
\hline 10 & 5 & 2,26 & 2,22 & 2,02 \\
\hline
\end{tabular}

NOTA.-CaO es lkgeramente soluble en agua. Asl, ocurre que una pequefit por ción de CaO libre se arrastre o disuelva en agua durante el curado de 1as probetas. Esta es la razon por la que el porcentaje de cal en la probeta de mortero sea ligeramente inferior a in de la muestra rectén preparada.-Los resultados de este método son inexactos si el cemento se mezcla con arena muy caliza o con cal libre. 